\title{
Effects of crowding on the three main proteolytic mechanisms of skeletal muscle in rainbow trout (Oncorhynchus mykiss)
}

Cristián A. Valenzuela ${ }^{1,2}$, Claudia Ponce ${ }^{1}$, Rodrigo Zuloaga ${ }^{1,3}$, Pamela González ${ }^{1,3}$, Ruben Avendaño-Herrera ${ }^{3,4,5^{*}}$, Juan A. Valdés ${ }^{1,3,5}$ and Alfredo Molina ${ }^{1,3,5^{*}}$ (i)

\begin{abstract}
Background: Skeletal muscle is one of the tissues most affected by stress conditions. The protein degradation in this tissue is vital for the supply of energy mediated by different proteolytic pathways such as the ubiquitinproteasome (UPS), autophagy-lysosome (ALS) and the calpain/calpastatin system (CCS). Nevertheless, the regulation of this proteolytic axis under stress conditions is not yet completely clear. Chile is the main producer of rainbow trout (Oncorhynchus mykiss) in the world. This intensive fish farming has resulted in growing problems as crowding and stress are one of the major problems in the freshwater stage. In this context, we evaluated the crowding effect in juvenile rainbow trout kept in high stocking density $\left(30 \mathrm{~kg} / \mathrm{m}^{3}\right)$ for 15,45 and 60 days, using a control group of fish $\left(10 \mathrm{~kg} / \mathrm{m}^{3}\right)$.
\end{abstract}

Results: Plasmatic cortisol and glucose were evaluated by enzyme immunoassay. The mRNA levels of stress-related genes (gr1, gr2, mr, hsp70, klf15 and redd1), markers of the UPS (atrogin1 and murf1) and CCS (capn1, capn1, cast-I and cast-s) were evaluated using qPCR. ALS (LC3-I/II and P62/SQSTM1) and growth markers (4E-BP1 and ERK) were measured by Western blot analysis. The cortisol levels increased concomitantly with weight loss at 45 days of crowding. The UPS alone was upregulated at 15 days of high stocking density, while ALS activation was observed at 60 days. However, the CCS was inactivated during the entire trial.

Conclusion: All these data suggest that stress conditions, such as crowding, promote muscle degradation in a time-dependent manner through the upregulation of the UPS at early stages of chronic stress and activation of the ALS in long-term stress, while the CCS is strongly inhibited by stress conditions in the rainbow trout muscle farmed during freshwater stage. Our descriptive study will allow perform functional analysis to determine, in a more detailed way, the effect of stress on skeletal muscle physiology as well as in the animal welfare in rainbow trout. Moreover, it is the first step to elucidate the optimal crop density in the freshwater stage and improve the standards of Chilean aquaculture.

Keywords: Fish, Stress response, Autophagy, Ubiquitin-proteasome, Calpain/calpastatin

\footnotetext{
*Correspondence: ravendano@unab.cl; reavendano@yahoo.com;

amolina@unab.cl

${ }^{3}$ Interdisciplinary Center for Aquaculture Research (INCAR), 4030000

Concepción, Chile

'Laboratorio de Biotecnología Molecular, Facultad de Ciencias de la Vida, Universidad Andrés Bello, 8370146 Santiago, Chile

Full list of author information is available at the end of the article
}

(C) The Author(s). 2020 Open Access This article is licensed under a Creative Commons Attribution 4.0 International License, which permits use, sharing, adaptation, distribution and reproduction in any medium or format, as long as you give appropriate credit to the original author(s) and the source, provide a link to the Creative Commons licence, and indicate if changes were made. The images or other third party material in this article are included in the article's Creative Commons licence, unless indicated otherwise in a credit line to the material. If material is not included in the article's Creative Commons licence and your intended use is not permitted by statutory regulation or exceeds the permitted use, you will need to obtain permission directly from the copyright holder. To view a copy of this licence, visit http://creativecommons.org/licenses/by/4.0/ The Creative Commons Public Domain Dedication waiver (http://creativecommons.org/publicdomain/zero/1.0/) applies to the data made available in this article, unless otherwise stated in a credit line to the data. 


\section{Background}

Chile is the main producer of rainbow trout (Oncorhynchus mykiss) in the world. This farming activities typically involve three distinct stages, namely, fresh water, smoltification (commonly in brackish waters), and life in the sea; and life in the sea, whose main objective to produce intensively with a lower economic cost. Due to the increase in demand for protein sources for human consumption, the salmon farming industry has had to adopt inappropriate practices to supply this demand, such as the use of high densities $\left(<30 \mathrm{~kg} / \mathrm{m}^{3}\right)$ of culture during the freshwater stage. In fact, the freshwater phase is unregulated on aspects such as fish density against the primary pathogens of this stage, such as Flavobacterium psychrophilum. This lack of regulation as compared to the seawater stages (10 to $15 \mathrm{~kg} / \mathrm{m}^{3}$ depending on the farmed species, i.e. trout or salmon) of the salmon lifecycle is surprising, increasing the vulnerability of the rainbow trout, especially since Chilean regulations on seawater rearing can often be stricter than other salmonid-producing countries, including Norway, Scotland, Ireland, and Canada [1]. Moreover, fish movements are an integral part of the Chilean salmon farming production cycle and has been recognized as a major risk for the introduction and spread of highly infectious diseases in fish. These practices cause a perturb in the animal welfare due to increase the stress, negatively impacting several different biological processes such as growth muscle as well as raising susceptibility of rainbow trout to bacterial and/or viral infection.

Skeletal muscle is the biggest tissue in fish and the most important protein source for human consumption; therefore, it is the most significant product for the fish industry [2]. The growth of muscle depends on the balance between anabolic and catabolic processes, and when the rate of degradation is greater than synthesis, the phenomenon of muscle atrophy is triggered [3]. Muscle atrophy derived from excessive proteolysis (catabolism) can lead to an inhibition of muscular growth [4]. In particular, three main mechanisms involved in the degradation of muscular protein are the ubiquitinproteasome system (UPS), the autophagy-lysosome system (ALS) and the calpain/calpastatin system (CCS) [5]. In fish, these processes have a key role in protein turnover and energy production [6].

Protein degradation by the UPS consists of the polyubiquitination of target proteins as a substrate for degradation; enzymes such as E1, E2 and E3 participate in this process and are key components in this mechanism [7]. In this system, the proteins are labeled for ubiquitination, then recognized by the $26 \mathrm{~S}$ proteasome complex and are degraded into oligopeptides [8]. However, in fish such as rainbow trout this system is responsible for only $17 \%$ of the protein degradation of myotubes [9]. The two specific markers for UPS in fish muscle are known as MurRF1 (Muscle RING-finger protein 1) and Atrogin $1[10,11]$. On the other hand, the ALS is responsible for more than $30 \%$ of total protein degradation of the skeletal muscle cells in fish [9]. In this process, portions of cytoplasm and cell organelles are sequestered into vesicles called autophagosomes, which then fuse with lysosomes or vacuoles for enzymatic breakdown [12]. At the molecular level, this mechanism is mediated by the conversion of LC3-I (Microtubule-associated protein 1A/1B-light chain 3) to the active form LC3-II and the degradation of P62/SQSTM1 protein content [13]. Finally, the CCS is involved in protein degradation during pre- and post- mortem events. This system has two main components: calpain and calpastatin, where calpains ( $\mu$-and $\mathrm{m}$-calpain) are $\mathrm{Ca}^{+2}$-dependent cysteine proteases, while calpastatin is the specific inhibitor of the calpain protease activity [14]. The function of this mechanism is mainly the degradation of muscle Z-discs [15].

In general terms, these three mechanisms can be modulated by different conditions and factors, stress being the most common and important for the fish aquaculture industry. Precisely, several routine conditions, such as confinement or crowding, handling, and vaccinations, can trigger the stress response, negatively impacting the productivity of this economic sector. For example, it is well documented that stress can inhibit the somatic growth of muscle in fish by downregulating the expression of growth-related genes in salmonids [16].

The stress response begins with activation of the hypothalamus-pituitary-interrenal (HPI) axis and the release of cortisol, the principal corticosteroid (CS) in fish [17]. After this primary stress response, cortisol can interact with the glucocorticoid receptors (GRs) and the mineralocorticoid receptor (MR) to promote the modulation of expression of different target genes of the GR/ MR [18]. Finally, biological processes, such as swimming ability, pathogen resistance, and growth rate, can be affected by stress in a response known as the tertiary stress response [19].

Several external factors can trigger a stress condition, such as high stocking density and food deprivation, and can directly and indirectly affect muscle growth, consequently promoting muscular atrophy in fish [20,21]. For example, the stress triggered by high stocking densities can activate different mechanisms involved in muscular atrophy such as the UPS in grass carp (Ctenopharyngodon idellus) [22]. In addition, in juvenile fine flounder (Paralichthys adspersus) subjected to 4 and 7 weeks of chronic stress, both the UPS and ALS were upregulated in a nonoverlapping way [4].

Despite these antecedents, little is known about the modulation of the UPS, ALS and CCS after long-term crowding stress in rainbow trout. In this context, the aim of this study was to analyze in detail these three 
processes at the molecular level in an integrative and descriptive manner using rainbow trout as a model system. For this, juvenile rainbow trout $(\sim 8 \mathrm{~g})$ were subjected to 15,45 and 60 days at two different densities: low density (LD) was set at $10 \mathrm{~kg} / \mathrm{m}^{3}$ and high density (HD) was set at $30 \mathrm{~kg} / \mathrm{m}^{3}$. Several UPS-related genes, ALS markers and CCS transcripts were assessed. Considering that Chile is the main producer of rainbow trout worldwide, studies like this are essential to have an approximation on the adequate culture density of salmonids farmed during the freshwater stage.

\section{Results}

\section{Morphometrical and stress parameters}

To evaluate the effect of crowding stress on morphological and molecular mechanisms of fish growth, juvenile trout were subjected to 15,45 and 60 days of treatment at two different densities (high [HD] and low [LD]). Body weight, total length and condition factor (K) in each experimental group are shown in Table 1. Significant differences where observed only in body weight at $45 \mathrm{HD}(P<0.05)$. In the HD groups, only at 45 days had plasma cortisol levels increased significantly compared with the LD group at the same time; however, a tendency can be observed at the other experimental times. There were no significant differences in plasmatic glucose (GLU) and total protein (TP) between LD and HD in the entire trial (Table 2). The corticosteroid receptors (CRs) gr1, gr2 and $m r$ were assessed, where only $g r 1$ was upregulated at $60 \mathrm{HD}$, while $g r 2$ did not change and $m r$ was downregulated at 45HD $(P<0.05)$ (Fig. 1a). The CR target genes redd 1 and klf15 $(P<0.01, P<0.05)$ and the stress marker $h s p 70$ were downregulated under HD conditions $(P<0.05)$ (Fig. 1b).

\section{Muscle growth signaling pathways}

Activation of the IGF-1/TOR and IGF-1/ERK signaling pathways was evaluated. The ratios of both $\mathrm{p} 4 \mathrm{E}-\mathrm{BP} 1 / 4 \mathrm{E}-$ BP1 and pERK/ERK were significantly downregulated at 15HD $(P<0.05)$ (Fig. 2a, b and Supplementary Figure S2).

\section{Ubiquitin-proteasome system gene expression}

Then, the gene expression of the "atrogenes" atrogin1 and murf1 was assessed. The mRNA level of murf1 was increased at 15HD $(P<0.0001)$ and then decreased at 45HD $(P<0.01)$, while atrogin1 mRNA levels did not change (Fig. 3a). Additionally, protein ubiquitination was observed and showed a significant increase at 60HD $(P<0.05)$ (Fig. 3b and Supplementary Figure S3).

\section{Autophagy-lysosome system molecular markers}

The autophagy proteins LC3 and P62/SQSTM1 were analyzed. The LC3-II/LC3-I protein content ratio was significantly upregulated only at 60HD $(P<0.001)$, whereas P62/SQSTM1 protein content did not change during the entire trial (Fig. 4a, b and Supplementary Figure S4).

\section{Calpain/calpastatin system expression and activity}

Finally, the calpain/calpastatin system was evaluated. At the transcriptional level, capn1 was significantly upregulated at 15HD $(P<0.05)$ while capn 2 mRNA levels decreased significantly at 60HD $(P<0.05)$ (Fig. 5a). On the other hand, cast- $l$ was downregulated at 15HD $(P<$ $0.05)$ and cast-s transcript levels increased $(P<0.01)$ in the same experimental time frame (Fig. $5 b)$. However, calpain activity was progressively downregulated during the entire trial $(P<0.05)$, reaching its lowest level at 60HD (Fig. 5c).

\section{Discussion}

Crowding stress can lead to an inhibition of muscle growth in fish, through muscular atrophy modulation $[4,21]$. Despite this, little is known about the molecular mechanisms involved in the promotion of muscle atrophy under stress conditions and the dynamic over time of these processes in rainbow trout, an aquatic species of great commercial interest worldwide. In this work, we showed the impact of crowding conditions on rainbow trout skeletal muscle through the molecular profile of the three main proteolytic mechanisms involved in muscular degradation. Classically, a complete stress response is represented by an increased level of cortisol and glucose in plasma, followed by the upregulation of the mRNA levels of several GR target genes such as klf15 and redd1 [23]. This modulation of gene expression can finally lead to an inhibition of muscle growth and other physiologic processes such as swim performance, reproduction and immune system function [19].

As a primary stress response, cortisol plasma levels increased significantly only at $45 \mathrm{HD}$. However, over the

Table 1 Values ( \pm standard deviation) of the morphological biometric parameters of rainbow trout (0. mykiss) at 15, 45 and 60 days of treatment. The results are shown as the means \pm SEM $(n=5$ per group) Significant differences shown with a line $(*=P<0.05)$

\begin{tabular}{|c|c|c|c|c|c|c|}
\hline & \multicolumn{2}{|l|}{15 Days } & \multicolumn{2}{|l|}{45 Days } & \multicolumn{2}{|l|}{60 Days } \\
\hline & $\mathrm{LD}$ & $\mathrm{HD}$ & $\mathrm{LD}$ & $\mathrm{HD}$ & $\mathrm{LD}$ & $\mathrm{HD}$ \\
\hline Body length $(\mathrm{cm})$ & $9 \pm 0.46$ & $9.6 \pm 0.24$ & $10.2 \pm 0.43$ & $9.5 \pm 0.35$ & $11.79 \pm 1.8$ & $11.62 \pm 1.17$ \\
\hline Body weight (g) & $8.74 \pm 1.34$ & $9.92 \pm 0.45$ & 12. $89 \pm 1.42$ & $9.81 \pm 0.379 *$ & $10.1 \pm 0.51$ & $10.5 \pm 0.4$ \\
\hline Condition factor (K) & $1.18 \pm 0.07$ & $1.12 \pm 0.05$ & $1.21 \pm 0.05$ & $1.15 \pm 0.10$ & $1.19 \pm 0.07$ & $1.16 \pm 0.12$ \\
\hline
\end{tabular}


Table 2 Plasma levels of cortisol, glucose and total proteins of rainbow trout (0. mykiss) at 15, 45 and 60 days of treatment. The results are shown as the means \pm SEM ( $n=5$ per group). Significant differences are shown with a line $\left({ }^{*}=P<0.05\right)$

\begin{tabular}{|c|c|c|c|c|c|c|}
\hline & \multicolumn{2}{|l|}{15 Days } & \multicolumn{2}{|l|}{45 Days } & \multicolumn{2}{|l|}{60 Days } \\
\hline & LD & $\mathrm{HD}$ & $\mathrm{LD}$ & $\mathrm{HD}$ & LD & $\mathrm{HD}$ \\
\hline Glucose (GLU) $\left(U^{-1}\right)$ & $173.68 \pm 9.93$ & $189.59 \pm 7.43$ & $193.85 \pm 3.79$ & $191.16 \pm 4.86$ & $187.82 \pm 3.73$ & $192.6 \pm 12.47$ \\
\hline Cortisol (mmol L-1) & $172.79 \pm 35.96$ & $346.79 \pm 69.52$ & $692.32 \pm 182.07$ & $1314.85 \pm 99.38^{*}$ & $482.13 \pm 108.07$ & $1045.73 \pm 474.71$ \\
\hline Total protein (TP) $\left(n g \mu L^{-1}\right)$ & $4.94 \pm 0.18$ & $4.68 \pm 0.16$ & $3.85 \pm 0.01$ & $3.46 \pm 0.24$ & $4.85 \pm 0.07$ & $5.1 \pm 0.12$ \\
\hline
\end{tabular}

entire trial, a tendency of cortisol levels to increase in both LD and HD groups was observed. Although it is well known that cortisol levels usually increase hours after exposure to a stressful condition in rainbow trout, zebra fish (Danio rerio) and gilthead seabream (Sparus aurata) [24], other studies have shown that cortisol levels increase significantly after 30 days of crowdingstress in rainbow trout [21]. Consequently, cortisol release can be associated with upregulation of the mRNA levels of the corticosteroid receptors $g r 1, g r 2$, and $m r$ [25] and the target genes of these receptors klf15 and redd1 [26]. Here, no concomitant increases in cortisol
A

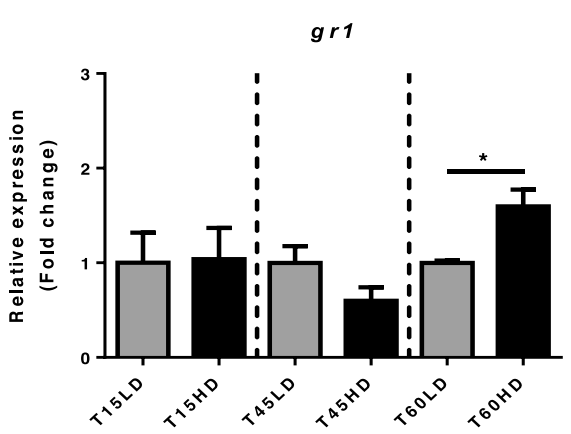

gr 2

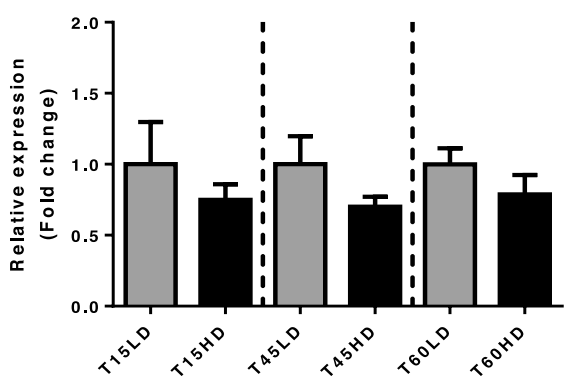

$m \boldsymbol{r}$

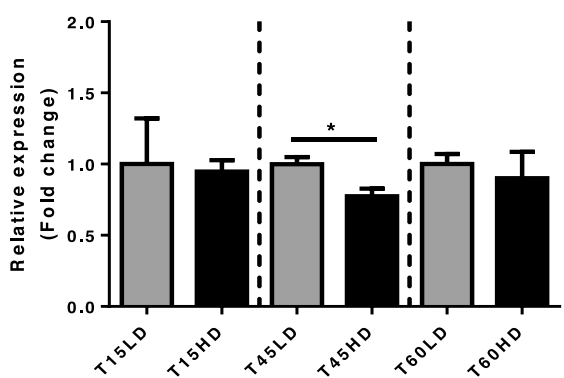

B

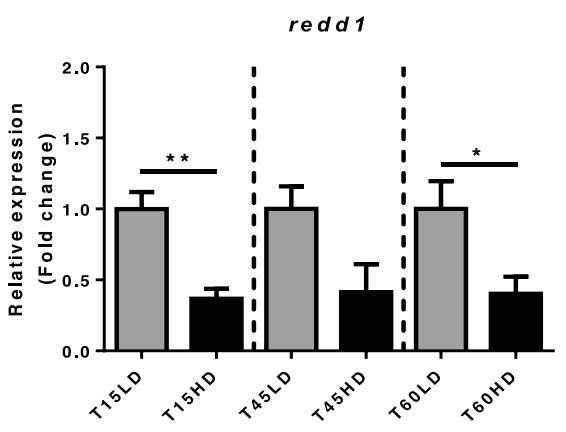

$k$ If1 5

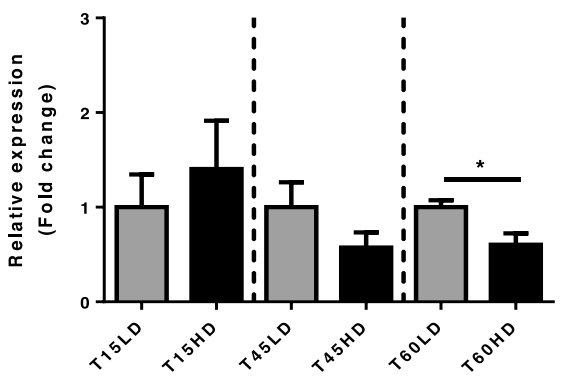

hsp 70

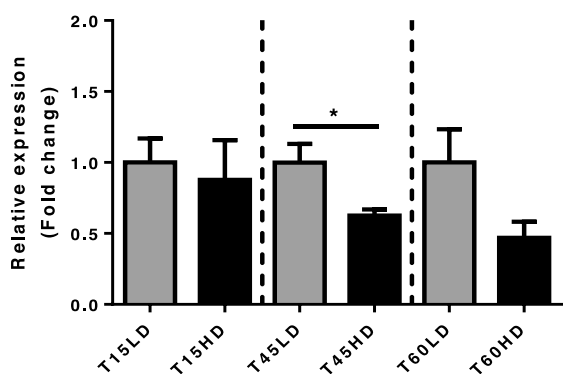

Fig. 1 High density-induced stress on the cortisol signaling pathway in skeletal muscle. Relative expression (fold change) of (a) corticosteroid receptors grl, gr2 and $\mathrm{mr}(\mathbf{b})$ GR target genes: redd1, klf15, and hsp70 normalized with fau and $\beta$-actin. Results are shown as the means \pm SEM ( $n=5$ per group). LD, low stocking density; HD, high stocking density. Significant differences are indicated with a line $\left(^{*}=P<0.05 ;{ }^{*}=P<0.01\right)$ 


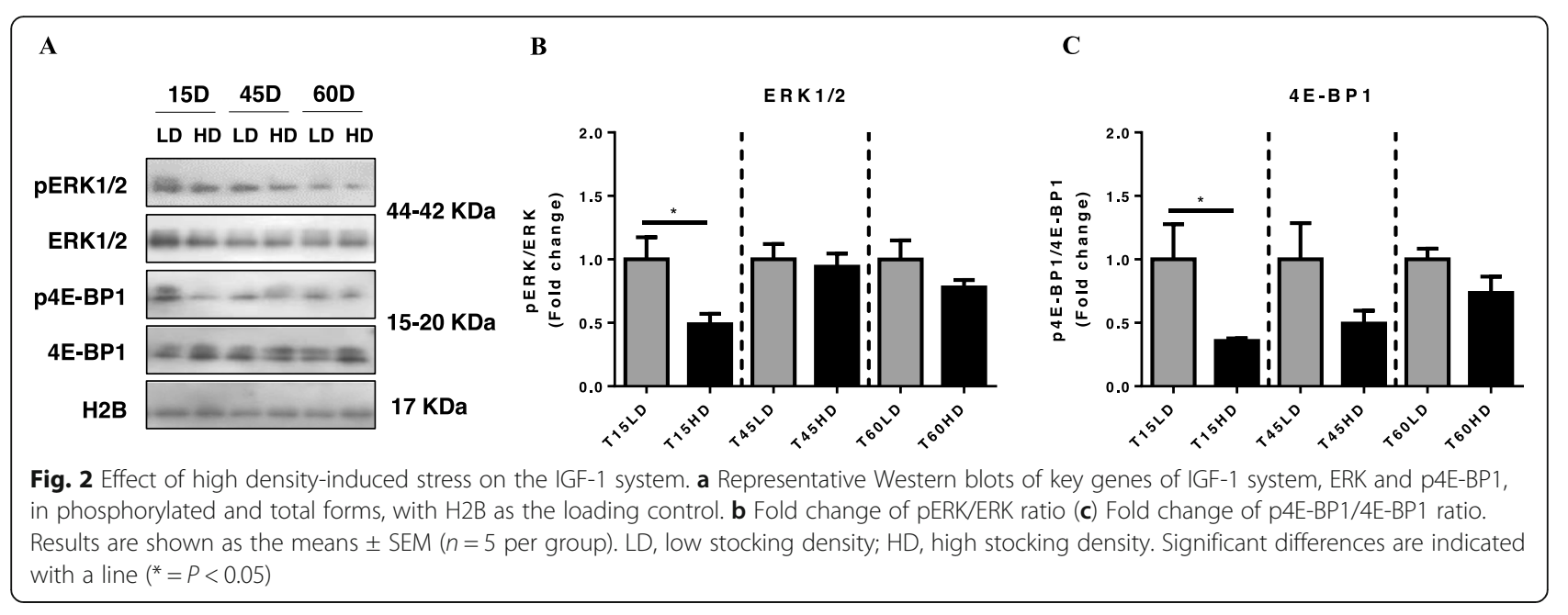

and CR transcript levels were observed, where grl was upregulated only at $60 \mathrm{HD}, \mathrm{mr}$ was downregulated at $45 \mathrm{HD}$, and gr 2 mRNA levels did not change. These results differ from those reported in other studies, where an increase in cortisol levels and CR mRNA levels have been observed within the same experimental time frame, suggesting an upregulation in the transcription of GR genes by cortisol [27]. Despite the upregulation of $g r 1$, the mRNA levels of the GR target genes klf15 and redd1 were downregulated, suggesting a negative regulation of the pathway associated with KLF15/REDD1 in trout under crowding stress. It is well known that these two molecules are involved in the promotion of atrophy and growth inhibition in fish muscle [4]. Particularly, REDD1 is involved in the inhibition of mTOR, a key molecule in the growth pathway IGF-1/Akt/mTOR [28]. In this study, growth pathways were downregulated at 15HD, where $\mathrm{pERK} / \mathrm{ERK}$ and $\mathrm{p} 4 \mathrm{E}-\mathrm{BP} 1 / 4 \mathrm{E}-\mathrm{BP} 1$ ratios were

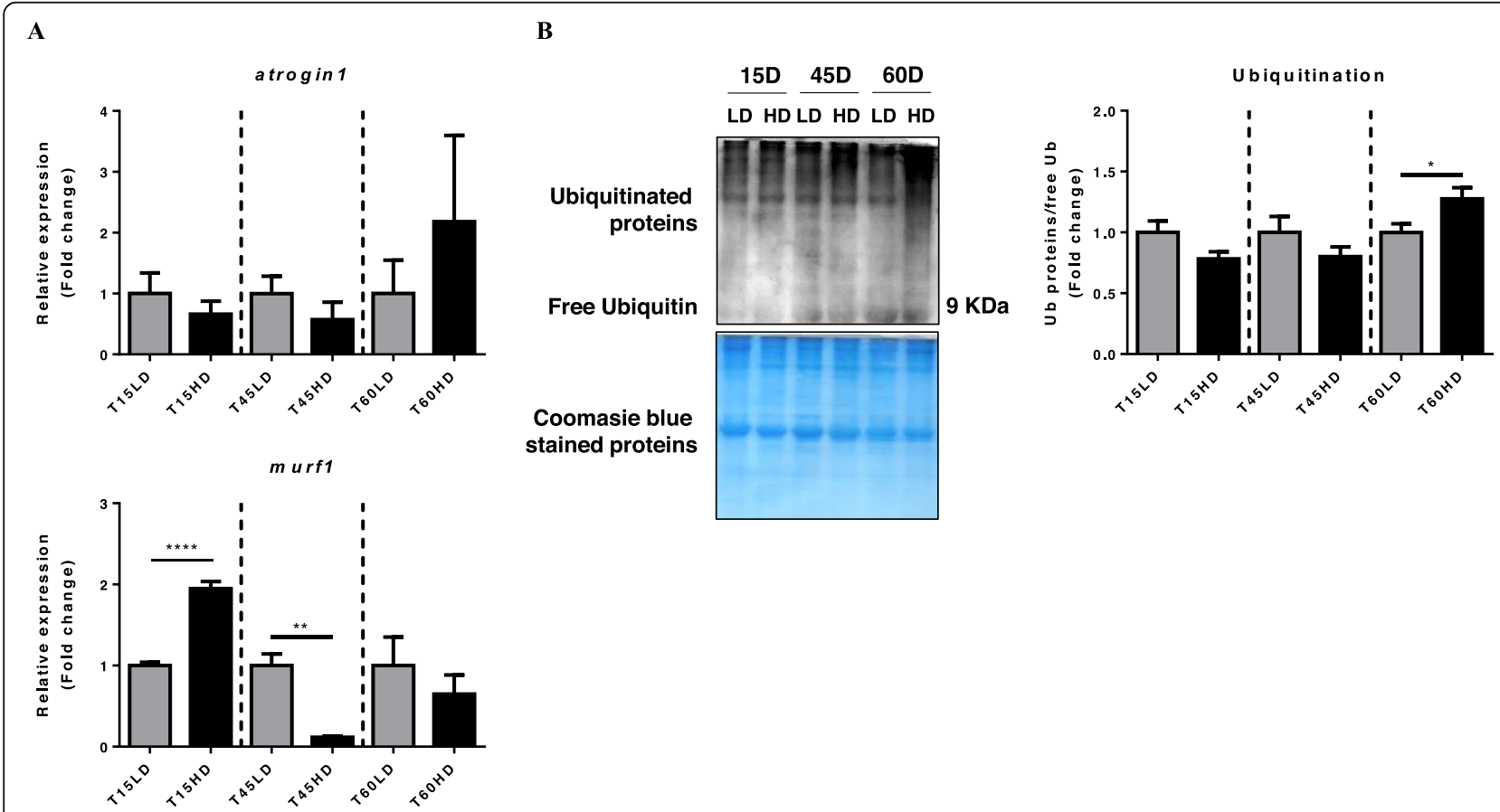

Fig. 3 Effect of high density-induced stress on the ubiquitin-proteasome system. a Relative expression (fold change) of key genes of the ubiquitin proteasome system, atrogin1 and murf1, normalized with fau and $\beta$-actin. b Representative Western Blot of Ubiquitinated proteins. Coomassie blue-stained loading control proteins. Fold change of ubiquitinated proteins/free ubiquitin ratio. Results are shown as the means \pm SEM ( $n=5$ per group). LD, low stocking density; HD, high stocking density. Significant differences are indicated with a line and an asterisk $\left({ }^{*}=P<0.05\right.$; $\left.{ }^{* *}=P<0.01 ;{ }^{* * * *}=P<0.0001\right)$ 


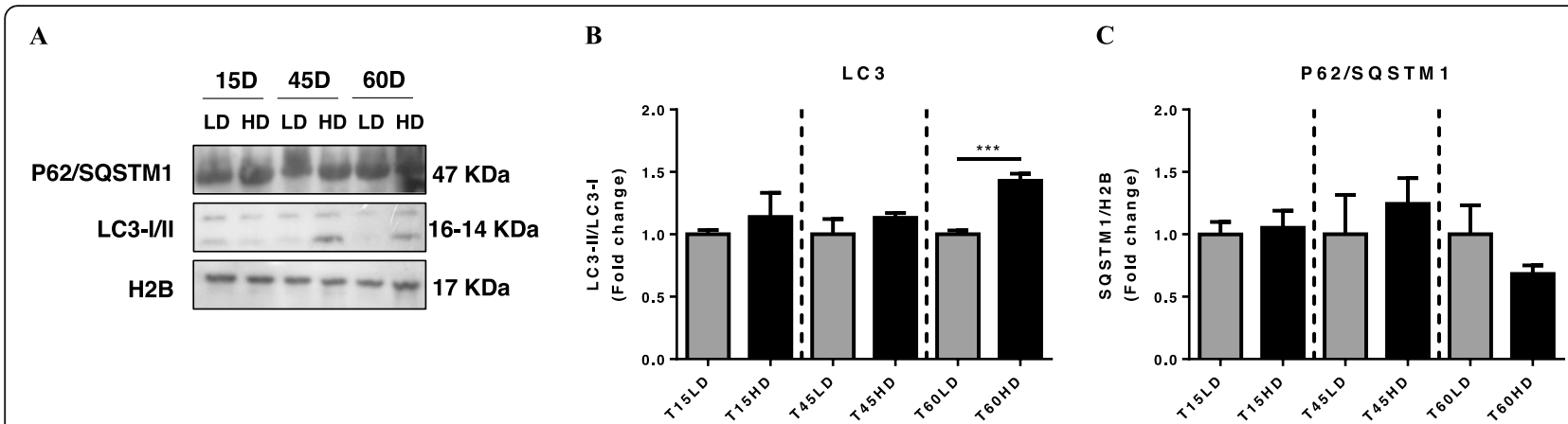

Fig. 4 Effect of high density-induced stress on the autophagy-lysosome system. Representative blots of the content of key proteins of autophagy system (a) LC3 II/I and (b) P62/SQSTM1 normalized with H2B. The results are shown as the means \pm SEM ( $n=5$ per group). LD, low stocking density; HD, high stocking density. Significant differences are indicated with an asterisk ( ${ }^{* * *}=P<0.001$ )

reduced, suggesting a reduction in protein synthesis and, consequently, an inhibition of growth. Similar effects were observed in teleost fish subjected to hypoxia, where it was determined that a decrease in protein synthesis during hypoxia is likely controlled by signaling molecules such as 4E-BP1 [29]. In the case of ERK, under nutritional stress, the phosphorylation of this molecule was downregulated in fine flounder [30]. A similar response was observed in the common carp (Cyprinus carpio), where under chronic exposure to fluoride, the ERK pathway was inactivated [31]. These antecedents, together with the results obtained in this work, suggest that the Akt/TOR pathway can be very sensitive to chronic stress conditions in fish at early stages (15 days of treatment).

One of the consequences of muscle growth inhibition can be the activation or promotion of muscle atrophy, which is carried out by different molecular processes such as UPS, ALS and CCS. In the present work, these three mechanisms showed different transcriptional behaviors, where at early time ( 15 days of crowding), the UPS was upregulated through an increase in murf1 gene expression. As a primary marker of protein degradation,

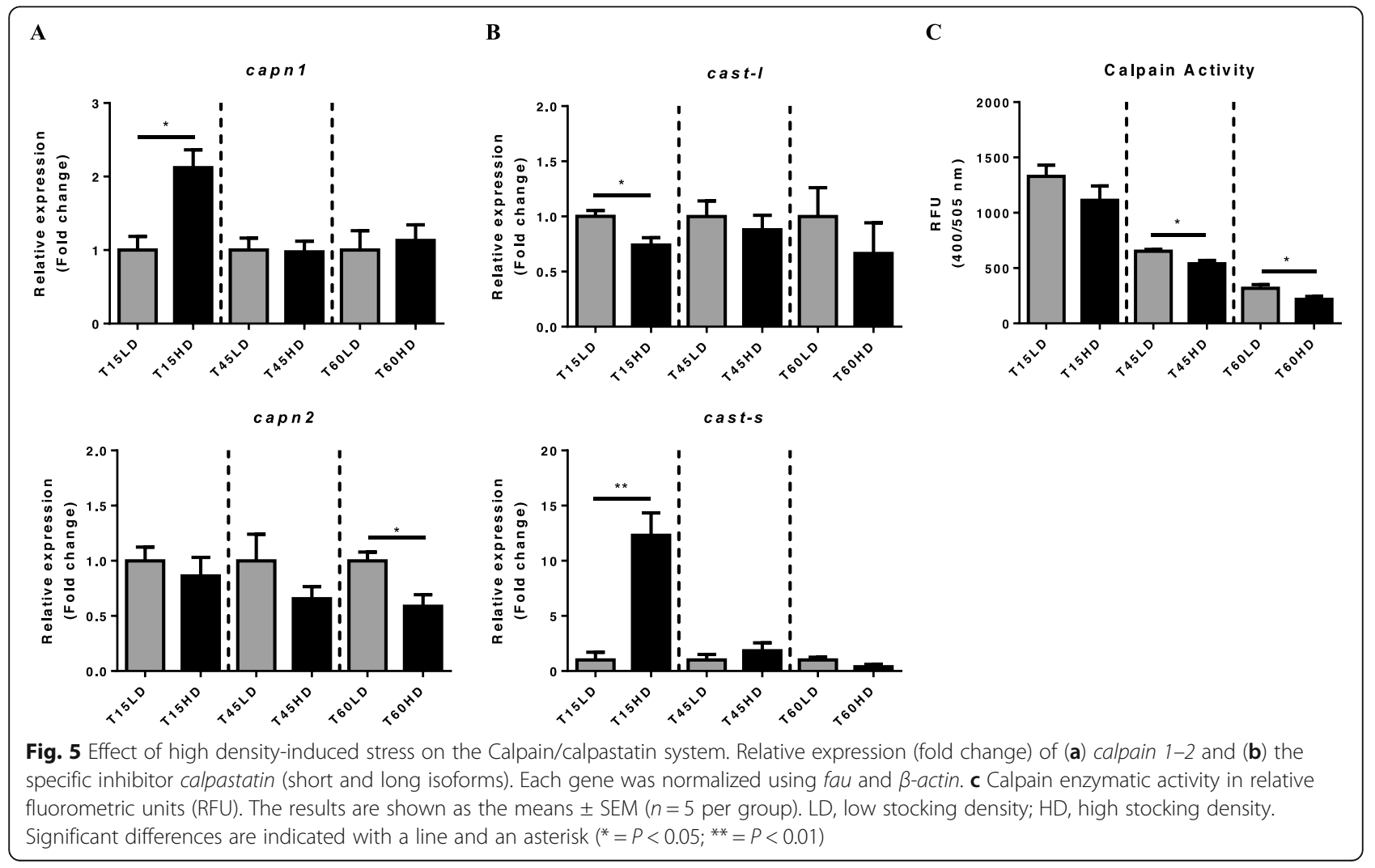


MuRF1 is a key E3 ligase involved in the control of the half-life of important muscle structural proteins, including troponin I, myosin heavy chains, myosin binding protein $\mathrm{C}$ and myosin light chains [32]. In contrast, with our results, low stocking densities promote UPS activity in grass carp (Ctenopharyngodon idella), suggesting that fish with better growth performance exhibited higher UPS activity in parallel with the activation of protein synthesis [22]. Despite these antecedents, in the present work we observed a concomitant upregulation of murf1 and activation of $4 \mathrm{E}-\mathrm{BP} 1$, suggesting that high stocking density exerted a potent effect on protein degradation and protein synthesis in the early stages of chronic stress (15 days of crowding).

Long term ( 60 days of high stocking density), only the ALS was upregulated in rainbow trout under crowding conditions. Autophagy constitutes the main mechanism for the degradation of unneeded components such as damaged/nonfunctional organelles and protein aggregates, to maintain the homeostasis of the cell [33]. This cellular mechanism is a dynamic process in which a double-membraned cytoplasmic vesicle, the autophagosome, selectively engulfs damaged proteins, organelles and fractions of cytoplasm and fuses with the lysosome (forming the autolysosome), degrading the sequestered components via lysosomal hydrolases [34]. One of the key molecules involved in the double-membrane vesicle formation is LC3 (Microtubule-associated protein 1A/ 1B-light chain 3), which is used as a specific marker of autophagy activation [35]. This molecule, in its inactive form LC3-I, is conjugated to phosphatidylethanolamine to form LC3-phosphatidylethanolamine conjugate (LC3II), which is recruited to autophagosome [36]. Although there are few studies that describe the effect of stress on autophagy in fish, in the last years this process has gained more attention due to its importance and implication in the regulation of cellular homeostasis. For example, $\mathrm{Lu}$ et al. (2019) [37] demonstrated that autophagy is involved in the protection of zebrafish under cold temperatures, preventing cell damage. However, in higher vertebrates the effect of stress over the autophagy is well characterized, where dexamethasone, a synthetic glucocorticoid, can upregulate autophagy, thereby promoting mitochondrial clearance [38]. Moreover, the importance of autophagy in skeletal muscle was reviewed by Neel et al. (2013) [39], who described that this process as a metabolic regulator that can be involved in several muscular diseases if it is dysregulated. In a previous work, we suggested that under chronic stress conditions, autophagy can play a cytoprotective role in fish; however, functional assays are required to corroborate this hypothesis.

Finally, we evaluated the expression profiles and activity levels of CCS, one of the most important groups of intracellular proteases in the muscle [40]. These molecules have been characterized in fish and used as markers of flesh quality and texture [14]. Despite this information, only a few reports have shown the transcriptional profile of these molecules under stress conditions, such as starving, where the mRNA levels of the calpains were upregulated $[14,15]$. In the present work, we observed a concomitant upregulation of capn1 and cast-s, while capn 2 and cast-l were downregulated at $15 \mathrm{HD}$ and $60 \mathrm{HD}$, respectively. While an increase in the expression of calpain 1 was observed, the enzymatic activity of these molecules gradually decreased during the experiment. This phenomenon was reviewed in mammals, where increased expression of calpain per se is unlikely to make a significant difference in activity [41]. Even more, less than $10 \%$ of total calpain is normally activated in mammalian skeletal muscle [42]. In this sense, chronic stress could negatively modulate activity of the calpains, which, as described in mammals, could be directly associated with the levels of calcium present in the muscle cells. To corroborate this, it is necessary to perform functional assays, which would allow us to quantitatively determine the implication of cytoplasmic calcium in fish stress models.

Scientific support on establishing the most appropriate densities in the farming of rainbow trout during the freshwater stage is essential. Not only for the rapid growth of fish, but also for animal welfare and less susceptibility to bacterial diseases that affect muscle such as F. psychrophilum [1]. Precisely, in Chile, there are no regulations associated with farming densities in this stage. In this context, the use of molecular parameters like genes used in the present work could allow define new strategies to improve the freshwater stage production of fish.

\section{Conclusion}

In summary, we descriptively showed the effect of chronic stress due to high stocking densities on the modulation, at the molecular level, of the three main proteolytic mechanisms in the rainbow trout skeletal muscle during freshwater phase. Here, we observed a time-dependent regulation of these mechanisms, where in the early stages of stress, the UPS was upregulated, while ALS was activated during long-term stress. Finally, the CCS was negatively regulated throughout the trial, progressively decreasing in activity until reaching its lowest level at the end of the experiment. The data obtained here could generate new government regulations for the farming of rainbow trout in Chile during freshwater stage and worldwide. In addition, this descriptive study will allow perform functional analysis to determine, in a more detailed way, the effect of stress on skeletal muscle physiology as well as in the animal welfare. 


\section{Methods}

\section{Fish husbandry, experimental design and sampling}

Juvenile and sexually immature rainbow trout (7.24 \pm $1.35 \mathrm{~g}$ body weight [mean \pm standard deviation]) from the same farming batch were randomly allocated among six different $8 \mathrm{~L}$ plastic tanks with aerated dechlorinated water at $15 \pm 1{ }^{\circ} \mathrm{C}$ and acclimatized for 1 week before the trial. The fish were fed with commercial pellets (Skretting, Chile) at $1.5 \%$ body weight daily and maintained with 12:12 h light:dark of photoperiod. Three tanks contained 10 individuals, corresponding to "low stocking density" (LD) rearing conditions $(10 \mathrm{~kg} / \mathrm{m} 3)$, and three tanks contained 30 individuals with "high stocking density" (HD) (30 kg/m3). Rainbow trout from LD and HD tanks were sampled at three experimental points: 15,45 and 60 days (hereafter mentioned as 15LD, 15HD, 45LD, 45HD, 60LD and 60HD). As the sampling requires removing the fish from each tank for euthanized, which affecting the density (i.e. decreases overcrowding), and it is not convenient to replace with other specimen kept in another pond and conditions. With the aim not to affect the results about the response of rainbow trout to density studied, we consider each density-by-tank combination was only sampled once. Five individual samples per tank ( $n=5$ per treatment) were randomly euthanized using an anesthetic overdose $\left(300 \mathrm{mg} / \mathrm{L}, \mathrm{BZ}-20^{\circ}\right.$, Veterquímica, Chile) at the same local time (1200) (experimental design in Supplementary information Figure S1). Blood from caudal vessel was collected using $1 \mathrm{~mL}$ heparinized $(10 \mathrm{mg} / \mathrm{mL})$ syringe, then centrifuged at $2000 \mathrm{x} \mathrm{g}$ for $5 \mathrm{~min}$ at $4{ }^{\circ} \mathrm{C}$ to collect plasma, immediately frozen in liquid nitrogen and stored at $-80^{\circ} \mathrm{C}$ until they were analyzed. After blood was collected, white myotome skeletal muscle was sampled from all fish, specifically a cross section from the epaxial area. Finally, samples were frozen by liquid nitrogen and stored at $-80^{\circ} \mathrm{C}$ until processed for RNA and protein extraction. The conduct of the experiment and outcome assessment were made in the laboratory of Dr. Ruben Avendaño-Herrera (Viña del Mar, Chile) and the data analysis were performed in the laboratory of Dr. Alfredo Molina (Santiago, Chile).

\section{Growth performance}

At the beginning and end of the trial, body weight (g) and total length $(\mathrm{cm})$ of each sampled fish were measured. Also, the condition factor (K) was calculated according previously described formula [30].

\section{Cortisol and glucose plasma levels}

Cortisol and Glucose plasma levels were analyzed by the Enzyme Immunoassay Kit (Cayman, USA) and glucose kit (Valtek Diagnostics, Chile), respectively, following the manufacturer's recommendations. Both commercial kits were previously validated in teleost fish $[43,44]$.

\section{Quantitative real time PCR (qPCR)}

Total RNA was isolated from $0.1 \mathrm{~g}$ of skeletal muscle following the manufacturer's recommendations of RNeasy $^{\circ}$ Mini Kit (Qiagen, USA). RNA was quantified by NanoDrop technology with Epoch Multi-Volume Spectrophotometer System (BioTek, USA). RNA quality was assessed by $1.2 \%$ formaldehyde agarose gel electrophoresis containing SafeView ${ }^{\text {тм }}$ Classic nucleic acid stain (Abm, Canada). Residual genomic DNA was removed, and $1 \mu \mathrm{g}$ was used for reverse transcription by Quantitect ${ }^{\oplus}$ reverse transcription kit (Qiagen, USA), according manufacturer's conditions. qPCR reactions were performed in a MX3000P thermocycler (Stratagene, USA). Each reaction mixture had $6 \mu \mathrm{l}$ of cDNA (a 40-fold dilution), 0.75 ul of each primer $(250 \mathrm{nM})$ and $7.5 \mu \mathrm{l}$ of $2 \times$ Brilliant $^{\oplus}$ II SYBR $^{\odot}$ master mix (Stratagene, USA) in a $15 \mu \mathrm{l}$ final volume. Primers were design using a similar approach that was previously described [4]. The primer sequences and their efficiency used in this study are listed in Table 3. Amplifications were made in triplicate using the following thermal cycling conditions: initial activation $95^{\circ} \mathrm{C}$ for $10 \mathrm{~min}, 40$ cycles of $30 \mathrm{~s}$ denaturation at $95^{\circ} \mathrm{C}, 30 \mathrm{~s}$ annealing at $56-63^{\circ} \mathrm{C}$, and $30 \mathrm{~s}$ elongation at $72^{\circ} \mathrm{C}$. Relative expression analysis was conducted using geNorm software (https://genorm.cmgg.be/) and the results were expressed as fold induction using $\beta$-actin and fau as stable reference genes.

\section{Western blotting}

The entire protocol in detail for western blotting was previously reported [4], with minor modifications. Briefly, after protein extraction from $0.1 \mathrm{~g}$ muscle samples, total protein contents were quantified using Pierce BCA Protein Assay Kit (Thermo Scientific, USA). Twenty-five $\mu \mathrm{g}$ of proteins were resolved in a 7-15\% SDS-PAGE and electro-transferred to PVDF membranes with Trans-blot Turbo Transfer System (Bio-Rad, USA). The membranes were blocked using 2\% ECL Prime blocking agent (GE Healthcare, UK) for $1 \mathrm{~h}$ at room temperature and then incubated with antibodies (phosphorylated, total and secondary antibodies) overnight at $4{ }^{\circ} \mathrm{C}$ in shaking. The commercial antibodies and dilutions used in this study are listed in Table 4. After washes, membranes were visualized by ECL Prime Western Blotting Detection Kit (GE Healthcare, UK). Also, membranes were immunoblotted against antiH2B for loading control (Abcam, UK). Finally, films were scanned for densitometric analysis of protein target bands and showing a representative blot film.

\section{Statistical analysis}

All data generated were evaluated by two-way ANOVA followed a Tukey's honestly significant difference (HSD) 
Table 3 Primer sequences for qPCR assay, amplicon size, PCR efficiencies, and GenBank accession numbers for the genes used in this study

\begin{tabular}{|c|c|c|c|c|c|}
\hline \multirow{2}{*}{$\frac{\text { Gene }}{40 S \text { ribosomal protein S30 (fau) }}$} & \multicolumn{2}{|c|}{ Sequence $5^{\prime}-3^{\prime}$} & \multirow{2}{*}{$\frac{\mathrm{TM}\left({ }^{\circ} \mathrm{C}\right)}{60}$} & \multirow{2}{*}{$\frac{\% E}{100 \%}$} & \multirow{2}{*}{$\frac{\text { GenBank code }}{\text { SRX612429 }}$} \\
\hline & Forward & CATTAAGGAGTTGGCGTTGG & & & \\
\hline & Reverse & CCAAGGTTGAAAAGCAGGAG & & & \\
\hline \multirow[t]{2}{*}{$\beta$-actin } & Forward & GCCGGCCGCGACCTCACAGACTAC & 65 & $103.6 \%$ & KC888023.1 \\
\hline & Reverse & GCCGGCCGCGACCTCACAGACTAC & & & \\
\hline \multirow[t]{2}{*}{ glucocorticoid receptor 1 (gr1) } & Forward & Teles et al. 2013 [45] & 58 & $101.2 \%$ & Z54210.1 \\
\hline & Reverse & & & & \\
\hline \multirow[t]{2}{*}{ glucocorticoid receptor 2 (gr2) } & Forward & Teles et al. 2013 [45] & 63 & $99.7 \%$ & AY495372.1 \\
\hline & Reverse & & & & \\
\hline \multirow[t]{2}{*}{ mineralocorticoid receptor (mr) } & Forward & Teles et al. 2013 [45] & 63 & $102.6 \%$ & AF209873.1 \\
\hline & Reverse & & & & \\
\hline \multirow[t]{2}{*}{ heat-shock protein 70 (hsp70) } & Forward & CATCGGTGAGTTCAAGCGTA & 60 & $98.30 \%$ & PRJNA518130 \\
\hline & Reverse & GCCCTGGTAATGGAGGTGTA & & & \\
\hline \multirow{2}{*}{$\begin{array}{l}\text { regulated in development and } \\
\text { DNA damage response } 1 \text { (redd1) }\end{array}$} & Forward & GGGGGAGGTGTGTCAGAGTA & 61 & $103.5 \%$ & XM_021615231 \\
\hline & Reverse & TTACGGGACTGGATGGAGAC & & & \\
\hline \multirow[t]{2}{*}{ krüppel-like factor 15 (klf15) } & Forward & GGAGAGGAGGAAGAGGAGG & 60 & $101.1 \%$ & XM_021609837.1 \\
\hline & Reverse & TGTTCAATGGAGCTGGAAGG & & & \\
\hline \multirow[t]{2}{*}{ F-box protein 32 (atrogin1) } & Forward & GAATCTGCGGCTGTCTGTT & 61 & $99.8 \%$ & NM_001195177.1 \\
\hline & Reverse & CCTCCTGTTGTCCTTGATGG & & & \\
\hline \multirow[t]{2}{*}{ muscle RING finger 1 (murf1) } & Forward & CAAGAGCATCGAGGAGAACAG & 61 & $97.40 \%$ & NC_035094.1 \\
\hline & Reverse & TCCTCTGTCACCACATCATCA & & & \\
\hline \multirow[t]{2}{*}{ calpain 1 (capn1) } & Forward & TCCTTTTGGAAGCCATTTT & 56 & $104.6 \%$ & AY573919.1 \\
\hline & Reverse & GGATATTGTGGGGGTTIT & & & \\
\hline \multirow[t]{2}{*}{ calpain 2 (capn2) } & Forward & GAAGGACAAGGATTTGGACG & 60 & $101.8 \%$ & AY573920.1 \\
\hline & Reverse & CCTGACAGAGCCTCATAGC & & & \\
\hline \multirow[t]{2}{*}{ calpastatin L (cast-I) } & Forward & CTCAGTAGCCGTGACAA & 56 & $102.2 \%$ & AY937407.1 \\
\hline & Reverse & GCTCTTGCCATCCTTATT & & & \\
\hline \multirow[t]{2}{*}{ calpastatin S (cast-s) } & Forward & GATGGGGGAGAGAGATGTCA & 62 & $100 \%$ & AY937408.1 \\
\hline & Reverse & ACTGGGCTGTGTCTGCTT & & & \\
\hline
\end{tabular}

Table 4 Types, dilutions, and other features of antibodies used to detect different proteins. The letter in the primary antibody dilution indicates the secondary dilution used

\begin{tabular}{|c|c|c|c|}
\hline Antibody & Dilution & Brand & Catalog $\mathrm{N}^{\circ}$ \\
\hline Sequestosome 1 (P62/SQSTM1) & 1:1000a & Abcam & 91,526 \\
\hline Microtubule-associated protein 1A/1B-light chain 3 (LC3A/B) & 1:1000a & Cell Signaling & 12,741 \\
\hline Phospho-Extracellular signal-regulated kinases 1/2 (pERK1/2) & $1: 2000 \mathrm{c}$ & Cell Signaling & 9106 \\
\hline Extracellular signal-regulated kinases 1/2 (ERK1/2) & $1: 2000 \mathrm{c}$ & Cell Signaling & 9107 \\
\hline Phospho-Eukaryotic translation initiation factor 4E-binding protein 1 (p4E-BP1) & 1:1000a & Cell Signaling & 9459 \\
\hline Eukaryotic translation initiation factor 4E-binding protein 1 (4E-BP1) & 1:1000a & Cell Signaling & 9452 \\
\hline Ubiquitin & $1: 2000 b$ & Cell Signaling & 3933 \\
\hline Histone 2B (H2B) & $1: 2000 \mathrm{~b}$ & Abcam & 17,901 \\
\hline Anti-rabbit lgG & $1: 2000 a$ & Cell Signaling & 7074 \\
\hline Anti-rabbit lgG & $1: 4000 b$ & Cell Signaling & 7074 \\
\hline Anti-mouse $\lg G$ & $1: 4000 c$ & Cell Signaling & 7076 \\
\hline
\end{tabular}


a-posteriori to determine specific differences between factors (density and time). Data are expressed as mean $(n=5$ per treatment $) \pm$ standard error of mean (SEM), and $p<0.05$ was considered statistically significant. All analyses were performed using general linear models using Graph Prism 7.0 software (GraphPad Software, Inc., USA).

\section{Supplementary information}

Supplementary information accompanies this paper at https://doi.org/10. 1186/s12917-020-02518-w.

Additional file 1: Figure S1. Graphical abstract of the experimenta design. Figure S2. Original western blot images used for growth signaling densitometric analysis. Figure S3. Original western blot and gel images used for ubiquitination densitometric analysis. Figure S4. Original western blot films scanned for autophagy densitometric analysis.

\section{Abbreviations}

ALS: Autophagy lysosome system; CAPN1: Calpain 1; CAPN2: Calpain 2; CASTL: Calpastatin long isoform; CAST-S: Calpastatin short isoform; CCS: Calpain/ calpastatin system; CS: Corticosteroid; ERK1/2: Extracellular signal-regulated kinase 1/2; FAU: 40 S ribosomal protein S30; GR1: Glucocorticoid receptor 1; GR2: Glucocorticoid receptor 2; HD: High stocking density; HSP70: Heat-shock protein 70; H2B: Histone 2B; IGF-1: Insulin-like growth factor 1;

KLF15: Krüppel-like factor 15; LC3: Microtubule-associated protein 1A/1B-light chain 3; LD: Low stocking density; MR: Mineralocorticoid receptor; MURF1: Muscle RING Finger 1; P62/SQSTM1: Sequestosome-1; qPCR: Quantitative real-time polymerase chain reaction; REDD1: Regulated in development and DNA damage responses 1; TOR: Target of rapamycin; UPS: Ubiquitin proteasome system; 4E-BP1: Eukaryotic translation initiation factor 4E-binding protein 1

\section{Acknowledgements}

The authors thank Dr. Jose Pulgar (Universidad Andrés Bello) for advice regarding statistical analyses.

\section{Authors' contributions}

CAV, JAV, RA-H and AM conceived and designed the experiment. CAV, CP, RZ, PG and RA-H performed the experiments. CAV analyzed and interpreted the results. CAV wrote the first draft of the manuscript. CAV and RA-H participated in the critical review of the manuscript. All authors read, commented on, and approved the final version of the manuscript.

\section{Funding}

Funding for this research was provided by the he Agencia Nacional de Investigación y Desarrollo (ANID, Chile) under Grant: FONDECYT Nº1171307 (to A. Molina); FONDECYT 1171318 (to J.A. Valdés) and Fondo de Financiamiento de Centros de Investigación en Áreas Prioritarias (FONDAP) Grants INCAR 15110027 (to J.A. Valdés, R. Avendaño-Herrera and A. Molina). Mention of trade names or commercial products in this article is solely for the purpose of providing specific information and does not imply recommendation or endorsement by the funders. Funding sources had no role in study design, data collection and analysis, decision to publish, or preparation of the manuscript.

\section{Availability of data and materials}

The nucleotide sequences used in this study were collected from the National Center for Biotechnology Information (NCBI) GenBank repository. The GenBank accession numbers of all sequences were listed in the Table 3. The commercial antibodies used in this study were listed in the Table 4 . The datasets generated and/or analyzed during the current study are not publicly available due to privacy or ethical restrictions, but are available from the corresponding author on reasonable request.

\section{Ethics approval and consent to participate}

A group of healthy pathogen-free rainbow trout $(7.24 \pm 1.35 \mathrm{~g}$ body weight [Mean and SD], $n=160$ ) were obtained from "Río Blanco Federico Albert Taupp" fish farm (Valparaíso Region), a hatchery with no history of disease (located in central Chile, Los Andes). This hatchery has the certificate of being free of pathogens included in Chilean List 1, 2 and 3. In addition, before moving fish, by sanitary regulations, fish were certificated as free of any pathogen described in Chile. All the experimental procedures and animal manipulations were designed and approved according to the ethical handling of live animals' standards from the Chilean National Commission of Scientific and Technological Research (CONICYT), and the Ethics Committee for Animal Experiments of the Universidad Andres Bello.

\section{Consent for publication}

Not applicable.

\section{Competing interests}

The authors declare that they have no competing interest.

\section{Author details}

'Laboratorio de Biotecnología Molecular, Facultad de Ciencias de la Vida, Universidad Andrés Bello, 8370146 Santiago, Chile. 'Laboratorio de Genética e Inmunología Molecular, Instituto de Biología, Pontificia Universidad Católica de Valparaíso (PUCV), Valparaíso, Chile. ${ }^{3}$ Interdisciplinary Center for Aquaculture Research (INCAR), 4030000 Concepción, Chile. ${ }^{4}$ Laboratorio de Patología de Organismos Acuáticos y Biotecnología Acuícola, Universidad Andrés Bello, 2520000 Viña del Mar, Chile. ${ }^{5}$ Centro de Investigación Marina Quintay (CIMARQ), Universidad Andrés Bello, 2340000 Quintay, Chile.

Received: 23 May 2019 Accepted: 7 August 2020

Published online: 17 August 2020

\section{References}

1. Avendaño-Herrera R. Proper antibiotics use in the Chilean salmon industry: policy and technology bottlenecks. Aquaculture. 2018;495:803-5.

2. FAO. 2018. El estado mundial de la pesca y la acuicultura 2018. Cumplir los objetivos de desarrollo sostenible. Roma. Licencia: CC BY-NC-SA 3.0 IGO.

3. Johnston I, Bower N, Macqueen D. Growth and the regulation of myotomal muscle mass in teleost fish. J Exp Biol. 2011;214(10):1617-28.

4. Valenzuela C, Zuloaga R, Mercado L, Einarsdottir I, Björnsson B, Valdés J, et al. Chronic stress inhibits growth and induces proteolytic mechanisms through two different nonoverlapping pathways in the skeletal muscle of a teleost fish. Am J Physiol Regul Integr Comp Physiol. 2018;314(1):R102-13.

5. Nemova N, Lysenko L, Kantserova N. Degradation of skeletal muscle protein during growth and development of salmonid fish. Russ J Dev Biol. 2016; 47(4):161-72.

6. Vélez E, Azizi S, Verheyden D, Salmerón C, Lutfi E, Sánchez-Moya A, et al. Proteolytic systems' expression during myogenesis and transcriptional regulation by amino acids in gilthead sea bream cultured muscle cells. PLoS One. 2017:12(12):e0187339.

7. Leestemaker $\mathrm{Y}, \mathrm{Ovaa} \mathrm{H}$. Tools to investigate the ubiquitin proteasome system. Drug Discov Today Technol. 2017;26:25-31.

8. Bell R, Al-Khalaf M, Megeney L. The beneficial role of proteolysis in skeletal muscle growth and stress adaptation. Skelet Muscle. 2016;6:16.

9. Seiliez I, Dias K, Cleveland B. Contribution of the autophagy-lysosomal and ubiquitin-proteasomal proteolytic systems to total proteolysis in rainbow trout (Oncorhynchus mykiss) myotubes. Am J Physiol Regul Integr Comp Physiol. 2014;307(11):R1330-7.

10. Bodine $\mathrm{S}$. Identification of ubiquitin ligases required for skeletal muscle atrophy. Science. 2001;294(5547):1704-8.

11. Valenzuela C, Escobar D, Perez L, Zuloaga R, Estrada J, Mercado L, et al. Transcriptional dynamics of immune, growth and stress related genes in skeletal muscle of the fine flounder (Paralichthys adpersus) during different nutritional statuses. Dev Comp Immunol. 2015;53(1):145-57.

12. He C, Klionsky D. Regulation mechanisms and signaling pathways of autophagy. Annu Rev Genet. 2009;43(1):67-93.

13. Yoshii S, Mizushima N. Monitoring and measuring autophagy. Int J Mol Sci. 2017;18(9):1865.

14. Salem M, Kenney P, Killefer J, Nath J. Isolation and characterization of calpains from rainbow trout muscle and their role in texture development. J Muscle Foods. 2005;15(4):245-55. 
15. Salem M, Yao J, Rexroad C, Kenney P, Semmens K, Killefer J, et al. Characterization of calpastatin gene in fish: its potential role in muscle growth and fillet quality. Comp Biochem Physiol B Biochem Mol Biol. 2005; 141(4):488-97.

16. Nakano T, Afonso L, Beckman B, Iwama G, Devlin R. Acute physiological stress down-regulates mRNA expressions of growth-related genes in Coho salmon. PLoS One. 2013;8(8):e71421.

17. Charmandari $\mathrm{E}$, Tsigos $\mathrm{C}$, Chrousos $\mathrm{G}$. Endocrinology of the stress response. Annu Rev Physiol. 2005;67(1):259-84.

18. Bury N, Sturm A. Evolution of the corticosteroid receptor signaling pathway in fish. Gen Comp Endocrinol. 2007;153(1-3):47-56

19. Barton B. Stress in fishes: a diversity of responses with particular reference to changes in circulating corticosteroids. Integr Comp Biol. 2002;42(3):517-25.

20. Midwood J, Larsen M, Aarestrup K, Cooke S. Stress and food deprivation: linking physiological state to migration success in a teleost fish. J Exp Biol. 2016;219(23):3712-8

21. Yarahmadi P, Miandare H, Fayaz S, Caipang C. Increased stocking density causes changes in expression of selected stress- and immune-related genes, humoral innate immune parameters and stress responses of rainbow trout (Oncorhynchus mykiss). Fish Shellfish Immunol. 2016;48:43-53.

22. Sun $Y$, Liang $X$, Chen J, Tang $R$, Li L, Li D. Change in ubiquitin proteasome system of grass carp Ctenopharyngodon idellus reared in the different stocking densities. Front Physiol. 2018;9:837.

23. McGhee N, Jefferson L, Kimball S. Elevated corticosterone associated with food deprivation upregulates expression in rat skeletal muscle of the mTORC1 repressor, REDD1. J Nutr. 2009;139(5):828-34.

24. Khansari A, Balasch J, Vallejos-Vidal E, Teles M, Fierro-Castro C, Tort L, et al. Comparative study of stress and immune-related transcript outcomes triggered by Vibrio anguillarum bacterin and air exposure stress in liver and spleen of gilthead seabream (Sparus aurata), zebrafish (Danio rerio) and rainbow trout (Oncorhynchus mykiss). Fish Shellfish Immunol. 2019;86:436-48.

25. Teles M, Boltaña S, Reyes-López F, Santos M, Mackenzie S, Tort L. Effects of chronic cortisol administration on global expression of GR and the liver transcriptome in Sparus aurata. Mar Biotechnol. 2012;15(1):104-14.

26. Shimizu N, Yoshikawa N, Ito N, Maruyama T, Suzuki Y, Takeda S, et al. Crosstalk between glucocorticoid receptor and nutritional sensor mTOR in skeletal muscle. Cell Metabol. 2011;13(2):170-82.

27. Yada T, Azuma T, Hyodo S, Hirano T, Grau E, Schreck C. Differential expression of corticosteroid receptor genes in rainbow trout (Oncorhynchus mykiss) immune system in response to acute stress. Can J Fish Aquat Sci. 2007;64(10):1382-9.

28. Wolff N, McKay R, Brugarolas J. REDD1/DDIT4-independent mTORC1 inhibition and apoptosis by glucocorticoids in thymocytes. Mol Cancer Res. 2014;12(6):867-77.

29. Cassidy A, Driedzic W, Campos D, Heinrichs-Caldas W, Almeida-Val V, Val A, et al. Protein synthesis is lowered by 4EBP1 and elF2-a signaling while protein degradation may be maintained in fasting, hypoxic Amazonian cichlids Astronotus ocellatus. J Exp Biol. 2017;221(2):jeb167601.

30. Fuentes E, Björnsson B, Valdés J, Einarsdottir I, Lorca B, Alvarez M, et al. IGFI/PI3K/Akt and IGF-I/MAPK/ERK pathways in vivo in skeletal muscle are regulated by nutrition and contribute to somatic growth in the fine flounder. Am J Physiol Regul Integr Comp Physiol. 2011;300(6):R1532-42.

31. Chen J, Cao J, Luo Y, Xie L, Song J, Xue W, et al. Expression of ERK and pERK proteins of ERK signaling pathway in the kidneys of fluoride-exposed carp (Cyprinus carpio). Acta Histochem. 2014;116(8):1337-41.

32. Bonaldo P, Sandri M. Cellular and molecular mechanisms of muscle atrophy. Dis Model Mech. 2012;6(1):25-39.

33. Sandri M. Autophagy in skeletal muscle. FEBS Lett. 2010;584(7):1411-6.

34. Martin-Rincon M, Morales-Alamo D, Calbet J. Exercise-mediated modulation of autophagy in skeletal muscle. Scand J Med Sci Sports. 2017;28(3):772-81.

35. von Muhlinen N. Methods to measure autophagy in cancer metabolism. Methods Mol Biol. 2019;1928:149-73.

36. Tanida I, Ueno T, Kominami E. LC3 and autophagy. Methods Mol Biol. 2008; 445:77-88.

37. Lu D, Ma Q, Wang J, Li L, Han S, Limbu S, et al. Fasting enhances cold resistance in fish through stimulating lipid catabolism and autophagy. J Physiol. 2019;597(6):1585-603.

38. Troncoso R, Paredes F, Parra V, Gatica D, Vásquez-Trincado C, Quiroga C, et al. Dexamethasone-induced autophagy mediates muscle atrophy through mitochondrial clearance. Cell Cycle. 2014;13(14):2281-95.
39. Neel B, Lin Y, Pessin J. Skeletal muscle autophagy: a new metabolic regulator. Trends Endocrinol Metab. 2013;24(12):635-43.

40. Lysenko L, Kantserova N, Kaivarainen E, Krupnova M, Nemova N. Skeletal muscle protease activities in the early growth and development of wild Atlantic salmon (Salmo salar L.). Comp Biochem Physiol B Biochem Mol Biol. 2017;211:22-8.

41. Costelli P, Reffo P, Penna F, Autelli R, Bonelli G, Baccino F. Ca2+-dependent proteolysis in muscle wasting. Int J Biochem Cell Biol. 2005;37(10):2134-46.

42. Goll D, Thompson V, Li H, Wei W, Cong J. The Calpain system. Physiol Rev. 2003;83(3):731-801.

43. Conde-Sieira M, Muñoz J, López-Patiño M, Gesto M, Soengas J, Míguez J. Oral administration of melatonin counteracts several of the effects of chronic stress in rainbow trout. Domest Anim Endocrinol. 2014;46:26-36.

44. Aedo J, Maldonado J, Aballai V, Estrada J, Bastias-Molina M, Meneses C, et al. mRNA-seq reveals skeletal muscle atrophy in response to handling stress in a marine teleost, the red cusk-eel (Genypterus chilensis). BMC Genomics. 2015;16(1).

45. Teles M, Tridico R, Callol A, Fierro-Castro C, Tort L. Differential expression of the corticosteroid receptors GR1, GR2 and MR in rainbow trout organs with slow release cortisol implants. Comp Biochem Physiol A Mol Integr Physiol. 2013;164(3):506-11. https://doi.org/10.1016/j.cbpa.2012.12.018.

\section{Publisher's Note}

Springer Nature remains neutral with regard to jurisdictional claims in published maps and institutional affiliations.
Ready to submit your research? Choose BMC and benefit from:

- fast, convenient online submission

- thorough peer review by experienced researchers in your field

- rapid publication on acceptance

- support for research data, including large and complex data types

- gold Open Access which fosters wider collaboration and increased citations

- maximum visibility for your research: over $100 \mathrm{M}$ website views per year

At $\mathrm{BMC}$, research is always in progress.

Learn more biomedcentral.com/submissions 